\title{
The Common Patterns of Brain Dominance and Its Effects on the Emotional Intelligence among the Faculty of Physical Education and Sport Science Students at the Hashemite University
}

\author{
Akef M Taifour ${ }^{1}$, Aman S Khasawneh ${ }^{1, *}$, Wasfi M Al-Kazaleh ${ }^{2}$, Salwa A Alshorman', \\ Haitham M Bani Eisa ${ }^{3}$, Gada M Khasawneh ${ }^{2}$, Malek S Khasawneh ${ }^{4}$ \\ ${ }^{1}$ Faculty of Physical Education and Exercise Science, the Hashemite University, Zarqa, 13133, Jordan \\ ${ }^{2}$ Faculty of Physical Education, Yarmouk University, Irbid, 21163, Jordan \\ ${ }^{3}$ Faculty of Educational Science, the Hashemite University, Zarqa, 13133, Jordan \\ ${ }^{4}$ Ministry of Education, Amman, Jordan
}

Received December 28, 2020; Revised April 6, 2021; Accepted April 18, 2021

\section{Cite This Paper in the following Citation Styles}

(a): [1] Akef M Taifour, Aman S Khasawneh, Wasfi M Al-Kazaleh, Salwa A Alshorman, Haitham M Bani Eisa, Gada M Khasawneh, Malek S Khasawneh, "The Common Patterns of Brain Dominance and Its Effects on the Emotional Intelligence among the Faculty of Physical Education and Sport Science Students at the Hashemite University," International Journal of Human Movement and Sports Sciences, Vol. 9, No. 3, pp. 503 - 512, 2021. DOI: 10.13189/saj.2021.090316.

(b): Akef M Taifour, Aman S Khasawneh, Wasfi M Al-Kazaleh, Salwa A Alshorman, Haitham M Bani Eisa, Gada M Khasawneh, Malek S Khasawneh (2021). The Common Patterns of Brain Dominance and Its Effects on the Emotional Intelligence among the Faculty of Physical Education and Sport Science Students at the Hashemite University. International Journal of Human Movement and Sports Sciences, 9(3), 503 - 512. DOI: 10.13189/saj.2021.090316.

Copyright $\odot 2021$ by authors, all rights reserved. Authors agree that this article remains permanently open access under the terms of the Creative Commons Attribution License 4.0 International License

\begin{abstract}
The purpose of this study is to determine the common patterns of brain dominance and the levels of the emotional intelligence of students, also the study aimed to recognize the variances of the common patterns as well as levels of the emotional intelligence according to the independent variables (gender, specialization, academic year), furthermore, the study identifies the variances of levels of the emotional intelligence among students according to the left, right and integrated dominance brain patterns. The Sample of study consisted of (329) male and female students who are chosen randomly from the faculty of physical education and sports science. The study used Othman and Rizk Emotional Intelligence Scale and Diane scale to measure the brain dominance after confirming its validity and reliability. The results of the study showed that the prevailing pattern among students was the integrated dominance brain patterns. Also, there was no significant effect of the independent variables (gender, specialization, academic year) on the left, right, and
\end{abstract}

integrated dominance brain patterns. Moreover, high levels of emotional intelligence, the results appeared no effect of the dominance brain pattern in the emotional intelligence.

Keywords Dominance Brain, Emotional Intelligence, Physical Education, the Hashemite University

\section{Introduction}

The developed countries always endeavor to build strong societies with highly qualified individuals. They should be able to face the modern life requirements which are full of stress and pressure that affect an individual psychology, personality, and rationality. It also affects individual's ability to communicate with the society around him as well as his ability in education to improve 
his performance and achievements.

The important, active, and vital role in this field became associated with the educational institutions, especially universities, which provide the society with experts of scientific researches. These scientific researches reduce effect of challenges, they regulate and treat them. They increase ability of education and the logical thinking.

Learning physical skills has a direct contact with the central nervous system, this require recruiting a brain completely because of different jobs of the two human brain hemispheres. All studies concerning brain agreed on existence of what is called the brain dominance for a human. The hemispheric dominance is a vital subject; it's combined with methods of thinking and education at universities and schools. But it hasn't been taught enough in sports field. Its main idea goes around using one of the two hemispheres (right or left) more than the other. This is called the dominant hemisphere or the leader hemisphere, because it directs individual's behavior. Using both of them will appear the integral pattern [1]. So one of the brain hemispheres should lead these jobs. Then this hemisphere is the leader hemisphere [2].

Many different fields support these studies, such as medicine, neurology, psychology, and pedagogy. These studies confirmed that the right and left hemispheres of human brain are working differently. They're not profoundly agreed with understanding the reality or the surrounding external world [3].

The concept of brain dominance is an individual's desire to depend on one hemisphere more than the other one in treating information [2]. Brain dominance means that one hemisphere is dominating on individuals' activities, or depending on one half more than the other in these activities.

As stated in some studies (Abraham et al., Asch) that the left hemisphere of brain is mainly specialized in treating linguistic, analytical, abstract, temporary, digital, and logical information, while the other hemisphere is mainly specialized in treating non-verbal, intuitive, total, symbolic, and potential information $[4,5]$.

Thus Solso points out about studies in fields of brain dominance show that the left hemisphere of a brain has a private jobs, such as languages, concepts, analysis, and classification, while the right hemisphere is associated with arts, music, and recognition of faces and shapes [6].

Based on the previous studies, some experts and researchers like (Razumnkiova; Torrance; Weinstein and Graves; Bowden and Jung-Beeman) consider that the right hemisphere of brain is responsible for the creative activity which uses an imagination, anticipation, and possibilities more than logic, and the defined detailed facts that come through convergent thinking $[7,8,9,10]$.

Jensen showed to the importance of brain dominance in treating and learning process, and directing thinking patterns of individuals. He focused on studying teaching and thinking methods, and brain preference throw declared the 1990s is a brain decade, which refers to the result of great discoveries which contributed in building and developing brain's jobs. This decade has a great effect in human history [11].

McCarthy showed the relation between brain dominance and thinking pattern in curriculums and individuals. It also has an effect in choosing crafts and academic specializations, some individuals choose their crafts or the academic branches (Scientific, literacy, agricultural, industrial, commercial, and nursing) according to their learning and thinking patterns, and the dominant hemisphere in their brains. The academic subjects such as law, Social sciences and architecture need comprehensive thinking pattern, this advantage makes them suitable for the right-brain dominance owners. On the other hand, other subjects, such as science, math, engineering, and languages are suitable for the left-brain dominance owners [12].

Accordingly on that reference [2] points to two thinking patterns among individuals based on the brain dominance: the logical thinking pattern which is one of the left hemisphere jobs. The creative thinking pattern which is one of the right hemisphere jobs.

Reference [13] pointed that the two hemispheres of brain are bound together by the Corpus Callasum which contains 420 million nerve lines. Also he explained that the right hemisphere is dealing with the overall things and dynamic skills, while the other hemisphere is dealing with languages and symbols. Reference [14] confirmed that the right hemisphere is responsible for translating symbols to movements.

In this regard, (Sham'on) indicated that the left hemisphere was the analyst, which used in learning new skills, correcting mistakes, and providing a player with information. But the other complementary hemisphere dominate was used to achieve a skill performance step by step under the lift hemisphere supervision [15].

There were different results for studies at universities and schools in Arab and foreign environments about using one of two hemispheres, the studies concluded that students use the left hemisphere more than the right hemisphere. Other studies pointed to the integration in using the two brain hemispheres and this different according to disciplines [16].

The emotional intelligence plays an important role in the educational and academic fields. This important role in different emotional states affects learning process to face conflict and discrepancy between individual's feeling and his ideas [17]. Some students suffer from dominant feelings such as frustration, anxiety, stress and fear which affect their achievements, while the positive feeling such as confidence, optimism, and motivation rise student's achievement and his ability to face challenges which are caused by the educational problems [18].

In the two latest decades in the past century researchers increased the importance of the emotional intelligence and 
its effect on the individual's life. It develops his abilities and helps him to get over pressures in his life. It also helps to achieve happiness, success, and making positive relations between each other [19, 20,39].

Emotional intelligence considered as an importance intelligent in the modern psychology; for its important role in human's life. It starts from a family, then reflects on Sons rearing, then extends to schools and universities where societies composition complete [21].

The individuals who have emotional intelligence are able to go with effects and changes of life and environment. They are the most successful in making personal relations, while individuals who can't control their emotions are suffering from self-control, moral deficiency, and inability to read their minds and passions $[22,23]$.

Undoubtedly intelligence is absolute weapon; its effects appear on all individuals' activities. Intelligent persons who have full requirements can reach to superiority, fame, and achieve more success whether in business field or in the sport field [24].

Emotions are type of expressions about interior reaction. Although emotions differ according to their causes, an exaggeration or immoderation in our emotions is considered Harmful to our interior body parts and physiological changes.

The emotional intelligence represents the essential skills that help normal individuals to achieve agreement and unity. So it should be increased profoundly because of its value in different fields to become more popular in the upcoming years. [25].

This study provides knowledge for educational individuals at universities; they can recognize the common brain dominance patterns among students and a level of the emotional intelligence. The study points to effects of brain dominance patterns on the emotional intelligence, this could help individuals to learn verbal skills and choose a suitable way to learn those skills according to the common brain dominance patterns and a level of the emotional intelligence. Additionally, there aren't enough studies concerning this subject in the local and Arab studies, so this study defines an effect of brain dominance and emotional intelligence in the motor learning process at the sport fields.

In the past years, there was a clear progress in studying individual's features and characteristics, especially with regard to his education, way of thinking and the effective environment. An individual success is relevant to the owned type of information and using them in thinking and learning in different situations, the brain dominance and emotional intelligence are active effects on individuals learning process of motor learning.

The brain dominance is one of the contributing factors in the educational process, especially if the educational environment is designed to affect different learning methods among students. From study brain dominance upon an individual, we can understand recognition process, information treatment process, and learning patterns of learners. Lecturers and teachers exploit implementations and discoveries of brain dominance to improve the educational process, as Soma sees its role in building the educational process [26].

The emotional intelligence is considered the key of success in the practical and social life. A student who acquires emotional intelligence can be able to achieve the academic intelligence feature; it can improve level of achievements for students through developing and acquiring the emotional intelligence.

Hence, the problem of this study coming from learning physical skill is attached directly to the central nervous system, this relation requires employing the brain completely because of the different jobs of the two brain hemispheres. Learning process requires positive environment away from stress and pressure.

The brain dominance is one of the modern vital subjects in the modern studies; it has great effect in thinking and learning methods at universities and schools. It hasn't been studied enough in sport field, even its effects on the psychological and mental state. So the idea of study comes to enhance and reveal concept of brain dominance role, the effect on learning motor skill, and role of the emotional intelligence in brain dominance.

So the purpose of the study is to answer the following questions:

The first question: What are the common brain dominance patterns among students?

The second question: What are the differences between common brain dominance patterns according to the independent variables (gender, specialization, academic year)?

The third question: What are the differences in the level of emotional intelligence according to the brain dominance patterns (left, right, integrated)?

\section{Materials and Methods}

\subsection{Study Design}

The design of this study was analytical descriptive method, it helps to recognize level of the emotional intelligence and the common brain dominance patterns among students of the faculty of physical education and sport science.

\subsection{Papulation and Sample}

The target population for this study was male and female students at physical education and sport science faculty in the Hashemite University enrolled for the second semester of the academic years 2018/2019. The sample for this study consisted of 329 students from (1034) 
as total community chosen randomly among students who accepted participation in the experiment and they constitute $31.82 \%$ of the total number of the society. And Table (1) shows the distribution of the sample according to the variables of the study.

Table 1. Explains description of the sample

\begin{tabular}{|c|c|c|c|}
\hline \multicolumn{2}{|c|}{ Variables } & Repetition & Percentage \\
\hline \multirow{4}{*}{ Gender } & Male & 149 & $45.29 \%$ \\
\cline { 2 - 4 } & Female & 180 & $54.71 \%$ \\
\cline { 2 - 4 } Specialization & Total & 329 & $100 \%$ \\
\hline & $\begin{array}{c}\text { Coaching } \\
\text { and sport } \\
\text { management }\end{array}$ & 261 & $79.33 \%$ \\
\cline { 2 - 4 } & $\begin{array}{c}\text { Sport } \\
\text { rehabilitation }\end{array}$ & 68 & $20.67 \%$ \\
\cline { 2 - 4 } & Total & 329 & $100 \%$ \\
\hline \multirow{5}{*}{ Academic Year } & First & 5 & $1.52 \%$ \\
\cline { 2 - 4 } & second & 78 & $23.71 \%$ \\
\cline { 2 - 4 } & Third & 136 & $41.34 \%$ \\
\cline { 2 - 4 } & Fourth & 92 & $27.96 \%$ \\
\cline { 2 - 4 } & Other & 18 & $5.47 \%$ \\
\cline { 2 - 4 } & Total & 329 & $100 \%$ \\
\hline
\end{tabular}

\subsection{Instruments}

Diane scale of brain dominance which translated to Arabic language by Qadumi (2010) was used in this study. It is 21 item instrument with two multiple choices in an answer that can determine the brain dominance patterns. One mark for each question, the highest mark is (21) [27, 1]. Also, Othman and Rizk for emotional intelligence Scale was used which consists of (58) items measuring the following five domains: (emotion management, empathy, emotional cognitive, social communication, and regulating emotions) with a five-way response scale [28]. Respondents were asked to rate items using a Likert-type scale with $1=$ Strongly Disagree; $2=$ Disagree; $3=$ Neither Disagree nor Agree; $4=$ Agree; and $5=$ Strongly Agree as anchors. All items have been drafted in the positive direction

\subsection{The Procedures}

The following processes were used to extract the results:

1. Official approval from faculty deanship and university administration were taken to implement the study.

2. Review previous educational literature relating to English and Arabic brain dominance and emotional intelligence studies in, such as: Qadumi; Abdelhaq \&Al-Ajeli; Al-Hamouri; Al-Rantesi; Qadumi; Othman \& Rizk; Diane; Robins \& Scott; McCarthy;
Bowden \& Jung-Beeman [1, 26, 34, 30, 28, 27, 26, 17, 11, 10].

3. According to the review, the researchers were selected Diane scale for brain dominance and Othman and Rizk for emotional intelligence Scale.

4. A panel of judges reviewed the questionnaires to ensure that the items are appropriateness, and the extent, linguistic clarity and probity, and to make any suggestions on this instrument.

5. Ensure scientific transactions for the instruments like validity, reliability and objectivity.

6. The study sample was determined to include male and female students, as well as students in coaching and sport management department and sport rehabilitation department from all academic years.

7. Applying the tow scales on the sample and collecting the required data.

8. Analyzing data and extracting results.

\subsection{Study Variables}

\section{- The Independent Variables}

(Gender: Males, Females; Specialization: Coaching and Sport Management, Sport Rehabilitation; the academic year: First, Second, Third, Fourth, Others).

\section{- The Dependent Variables}

(Brain Dominance Patterns, Emotional Intelligence).

\subsection{Data Collection Procedures}

Once consent forms were received from dean, arrangements were made by the researchers to administer the surveys or get the appropriate number of surveys. Coordination with the head departments was made to apply surveys through a general announcement for the students. The sample was comprised of the students who granted permission to participate in the study. Students were solicited on a voluntary basis after a full explanation of informed consent and confidentiality. Students were also asked to sign a consent form, which further explained the study. All data were collected in a manner that insured anonymity of participants and were treated confidentiality. The packets containing consent forms, pencils, questionnaires, and instructions were hand delivered immediately following each student by researchers. Once students completed the questionnaires, he delivered it to researchers. After collecting the completed surveys, it were arrangement, classification, creation of data files, and data analyses followed.

\subsection{Data Analysis}

The first research question asked, "What are the common brain dominance patterns among students according to the independent variables (gender, 
specialization, and academic year)" Repetitions and percentages were used to answer research question. Also, the second research question asked, "What are the differences between common brain dominance patterns according to the independent variables (gender, specialization, academic year)" Chi-square test was used to answer research question. As well, the third research question asked, "What are the differences in the level of emotional intelligence according to the brain dominance patterns (left, right, integrated)" one way ANOVA test was used to answer research question.

\section{Results and Discussion}

To answer the first question which refers to "What are the common brain dominance patterns among students according to the independent variables (gender, specialization, and academic year)?" Repetitions and percentages were used, and table 2 shows that.

From the table we can noted that the common pattern in gender variable was the integrated pattern, both of them males (102) and females (118). Right-brain dominance pattern had the second rank with repetition (26) among males sample, while had the third rank with repetition (27) among females sample. Left brain dominance pattern had the third rank with repetition (21) for males sample while had the second rank with repetition (35) for females sample.

In specialization variable, the integrated pattern had got the first rank among students of management and sport coaching, and physical rehabilitation specialization. Number of repetitions among students of management and sport coaching specialization are (172), whereas among students of sports rehabilitation specialization are (48). The second rank is the right-brain dominance pattern among students of management and sport coaching specialization (45) repetitions, then had the third rank among students of sports rehabilitation specialization (8) repetitions. Left-brain dominance pattern had the third rank among students of management and sport coaching specialization (44) repetitions, then had the second rank among students of sports rehabilitation specialization (12) repetitions.

While regarding to academic year variable, the common dominance brain pattern was the integrated pattern, numbers of repetitions are sequentially $(4,55,81,66,14)$ for the first, second, third, fourth year, and others. The second rank was the right-brain dominance pattern among students of the first, fourth year, and others with repetitions are sequentially $(1,14,3)$, while had third rank among students of the second and third year, the repetitions are $(14,29)$. The second rank was the left pattern among students of the second and third years with repetitions are $(9,26)$, while had third rank among students of the first year, fourth year, and others, the repetitions are $(0,12,1)$. Generally, it's a clear form the result that the common pattern was integrated pattern then left pattern and right pattern respectively.

The researchers believe that the reason for this is due to the nature of sports performance, which requires effectively integrate between left and right brain dominance patterns. In this regard, (Sham'on) indicated that the left hemisphere was the analyst, which was used in learning new skills, correcting mistakes, and providing a player with information. But the right hemisphere was complement which was used to achieve a skill performance step by step under the lift hemisphere

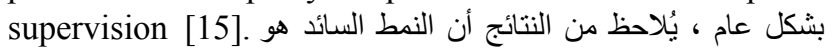
Generally, it is noted that the results of the pattern is complementary style and then left and then right style بشكل عام ، يلاحظ أن نتائج النمط هي لمي Can't load full results

Try again

Retrying...

Retrying...

This result attributed to what Qadumi indicated that ideal usage of the brain among university students, and the advantages of the right and left patterns due to the nature of the subjects they study which requires integration between the theoretical and practical sides which contributes to the optimal employment of the brain and not being limited to one side regardless the other. All these due to the large number of situations that students are exposed to, [29].

The result also agrees with (Al-Rantesi; Al-Qur'an and Al-Hamouri) studies, which pointed that the common brain dominance pattern among football players is the integrated pattern [30, 31], and (Ozrail) study which referred that the integrated pattern was the common for Palestine volleyball players [32]. Whereas, the result disagreed with (Nofal; Al-Hamouri) studies which pointed to the left pattern was the common among their samples $[33,34]$. References [26, 35] pointed to the right pattern which was the common pattern among their samples. 
The Common Patterns of Brain Dominance and Its Effects on the Emotional Intelligence

among the Faculty of Physical Education and Sport Science Students at the Hashemite University

Table 2. Brain dominance patterns repetitions and percentages according dependent variables

\begin{tabular}{|c|c|c|c|c|c|c|c|c|c|}
\hline & & \multicolumn{7}{|c|}{ Pattern Type } & \\
\hline \multicolumn{2}{|c|}{ Variables } & \multicolumn{2}{|c|}{ Left } & \multicolumn{2}{|c|}{ Right } & \multicolumn{2}{|c|}{ Integral } & \multirow{2}{*}{$\begin{array}{c}\text { Total } \\
\text { Repetition }\end{array}$} & \multirow[b]{2}{*}{ Percentage } \\
\hline & & Repetition & Percentage & Repetition & Percentage & Repetition & Percentage & & \\
\hline \multirow{3}{*}{ Gender } & Male & 21 & $6.38 \%$ & 26 & $7.9 \%$ & 102 & $31 \%$ & 149 & $45.29 \%$ \\
\hline & Female & 35 & $10.64 \%$ & 27 & $8.21 \%$ & 118 & $35.87 \%$ & 180 & $54.71 \%$ \\
\hline & total & 56 & $17.02 \%$ & 53 & $16.11 \%$ & 220 & $66.87 \%$ & 329 & $100 \%$ \\
\hline \multirow{3}{*}{ Specialization } & $\begin{array}{c}\text { Management and sport } \\
\text { coaching }\end{array}$ & 44 & $13.37 \%$ & 45 & $13.68 \%$ & 172 & $52.28 \%$ & 261 & $79.33 \%$ \\
\hline & Sports rehabilitation & 12 & $3.65 \%$ & 8 & $2.43 \%$ & 48 & $14.59 \%$ & 68 & $20.67 \%$ \\
\hline & Total & 56 & $17.02 \%$ & 53 & $16.11 \%$ & 220 & $66.87 \%$ & 329 & $100 \%$ \\
\hline \multirow{6}{*}{ Academic Year } & First & 0 & $0 \%$ & 1 & $0.30 \%$ & 4 & $1.22 \%$ & 5 & $1.52 \%$ \\
\hline & Second & 14 & $4.25 \%$ & 9 & $2.74 \%$ & 55 & $16.72 \%$ & 78 & $23.71 \%$ \\
\hline & Third & 29 & $8.82 \%$ & 26 & $7.90 \%$ & 81 & $24.62 \%$ & 136 & $41.34 \%$ \\
\hline & Fourth & 12 & $3.65 \%$ & 14 & $4.25 \%$ & 66 & $20.06 \%$ & 92 & $27.96 \%$ \\
\hline & Others & 1 & $0.30 \%$ & 3 & $0.91 \%$ & 14 & $4.25 \%$ & 18 & $5.47 \%$ \\
\hline & Total & 56 & $17.02 \%$ & 53 & $16.11 \%$ & 220 & $66.87 \%$ & 329 & $100 \%$ \\
\hline
\end{tabular}


Table 3. Explains results of Chi-square test for differences of the brain dominance patterns according to the variable independent (gender, specialization, academic year)

\begin{tabular}{|c|c|c|c|c|c|c|c|}
\hline \multirow{2}{*}{\multicolumn{2}{|c|}{ variables }} & \multicolumn{3}{|c|}{ Type } & \multirow{2}{*}{ Chi-square } & \multirow{2}{*}{$\mathrm{df}$} & \multirow{2}{*}{ Asymp. sig } \\
\hline & & left & right & integrated & & & \\
\hline \multirow{2}{*}{ Gender } & male & 21 & 26 & 102 & \multirow{2}{*}{1.777} & \multirow{2}{*}{2} & \multirow{2}{*}{0.411} \\
\hline & female & 35 & 27 & 118 & & & \\
\hline \multirow{2}{*}{ Specialization } & $\begin{array}{l}\text { management and } \\
\text { coaching }\end{array}$ & 44 & 45 & 172 & \multirow{2}{*}{1.201} & \multirow{2}{*}{2} & \multirow{2}{*}{0.548} \\
\hline & rehabilitation & 12 & 8 & 48 & & & \\
\hline \multirow{5}{*}{ Academic year } & first & 0 & 1 & 4 & \multirow{5}{*}{8.504} & \multirow{5}{*}{8} & \multirow{5}{*}{0.386} \\
\hline & second & 14 & 9 & 55 & & & \\
\hline & third & 29 & 26 & 81 & & & \\
\hline & fourth & 12 & 14 & 66 & & & \\
\hline & other & 1 & 3 & 14 & & & \\
\hline
\end{tabular}

To answer the second question which refers to "'What are the differences between common brain dominance patterns according to the independent variables (gender, specialization, academic year)?" Chi-square test is used, and table 3 show that.

It is showed in the table that there are no significant differences in the patterns of the brain dominance (left, right, integrated), according to the independent variables (gender, specialization, academic year). The value of its chi- square sequently amounted to $(1.777,1.201,8.504)$, and the levels of real significance differences amounted to $(0.411,0.548,0.86)$ sequently. All of them are higher than the level of significance $(a \leq 0.05)$ that points out to non-existent statistically significant differences in the patterns of the brain dominance according to gender, specialization, and academic year.

This result can be attributed to fact that the students of the university are facing the same teaching methods, the same curriculum and assigned the same educational activities by teachers. Furthermore, they encounter in the same educational environment and are having the same culture approximately. University institutions are able to perform a positive and important role in energizing and integrating both hemispheres of the brain in terms of processing information and thus help to improve the capabilities of the individuals in high levels. Humanitarian specializations might be the reason for that because they give bigger opportunities to a completely and flexibly deal with the phenomena that are related to them. University curricula and all academic activities which are related don't differ too much from level to another level in terms of their relationship to any activities of the brain hemispheres.

This result is consistent with references $[34,36]$ that pointed out to non-significant differences attributed to the gender of student in the brain dominance. Moreover, it is consistent with (Hamoda) study that referred to non-significant differences in the patterns of brain dominance attributed to gender and specialization variables [26]. Also, agrees with (Sulaymani) research that pointed out to non-significant differences in the patterns of brain dominance attributed to specialization variable [37]. Moreover, agrees with the results of (Ozrail) research that pointed out to non-significant differences in the brain dominance for volleyball players in Palestine attributed to the variables of club's degree, Centre of playing, experience and qualification [32].

While it disagrees with the references [38, 35, and 33] that pointed out to significant differences in patterns of brain attributed to specialization variable. Also, reference [1] pointed out to significant differences in the brain dominance for football players attributed to the variables of club level and in favor of the high level, center of playing in favor of mid line players and high experience.

To answer the third question which refers to "What are the differences in the level of emotional intelligence according to the brain dominance patterns (left, right, integrated)?" one way ANOVA test has been used, and table 4 show that. 
The Common Patterns of Brain Dominance and Its Effects on the Emotional Intelligence among the Faculty of Physical Education and Sport Science Students at the Hashemite University

Table 4. The results of one-way Anova test for the effect of brain dominance patterns on emotional intelligence

\begin{tabular}{|c|c|c|c|c|c|c|}
\hline \multicolumn{2}{|c|}{ Variables } & $\mathrm{N}$ & Minimum & Maximum & Mean & Std. Deviation \\
\hline \multicolumn{2}{|c|}{ Left-brain dominance pattern } & 56 & 2.68 & 4.21 & 3.4832 & .38728 \\
\hline \multicolumn{2}{|c|}{ Right- brain dominance pattern } & 53 & 2.93 & 4.49 & 3.6790 & .35138 \\
\hline \multicolumn{2}{|c|}{$\begin{array}{l}\text { Integrated-brain dominance } \\
\text { pattern }\end{array}$} & 220 & 2.02 & 5.00 & 3.6256 & .45915 \\
\hline \multicolumn{2}{|c|}{$\begin{array}{l}\text { Total sum of emotional } \\
\text { intelligence }\end{array}$} & 329 & 2.02 & 5.00 & 3.6100 & .43559 \\
\hline \multicolumn{7}{|c|}{ Anova } \\
\hline & \multicolumn{2}{|c|}{ Sum of Squares } & df & Mean Square & $\mathrm{F}$ & Sig. \\
\hline Between Groups & \multicolumn{2}{|c|}{1.207} & 2 & .603 & \multirow{3}{*}{3.233} & \multirow{3}{*}{0.041} \\
\hline Within Groups & \multicolumn{2}{|c|}{60.839} & 326 & .187 & & \\
\hline Total & \multicolumn{2}{|c|}{62.046} & 328 & & & \\
\hline
\end{tabular}

It is showed from the table that the mean for whole scale of emotional intelligence amounted to (3.6100), while the mean of the emotional intelligence level for the right pattern had the first rank and amounted to (3.6790) while left brain dominance got the last rank with mean amounted to (3.4832). All these means are considered high because they are above mean.

It is clear regarding the effect of the brain dominance on the level of the emotional intelligence that the value of F-test amounted to (3.233), and the p-value amounted to $(.041)$, it is below the $(a \leq 0.05)$. That points out to the existence of significant differences in the level of the emotional intelligence according to the patterns of brain dominance. And to find the trend of differences to any groups the scheffe test for post hoc comparison was used and table 5 show that.

Table 5. Scheffe test results for the post hoc comparisons between brain dominance patterns on emotional intelligence

\begin{tabular}{|c|c|c|c|c|}
\hline (I) type & (J) type & $\begin{array}{c}\text { Mean } \\
\text { Difference (I-J) }\end{array}$ & $\begin{array}{c}\text { Std. } \\
\text { Error }\end{array}$ & Sig. \\
\hline left & right & -.19586 & .08279 & 0.062 \\
\hline left & integrated & -.14242 & .06466 & 0.090 \\
\hline right & integrated & .05343 & .06610 & 0.722 \\
\hline
\end{tabular}

It is cleared from the table that the differences appeared in favor to the right brain dominance which have the highest mean, but these differences between groups are not statistically significant because the levels of real significance differences amounted to $(0.062,0.090,0.722)$ respectively, and all of them are higher than the level $(a \leq 0.05)$. The reason for this can be attributed to the high levels of emotional intelligence in all brain dominance patterns groups.

And this what the literature review related to brain dominance emphasizes on it, it points out that the left hemisphere of the brain is specialized specifically in processing the linguistic, analytic, abstract, temporary, digital, and logical information. The right hemisphere of the brain is specifically specialized in processing non-verbal, locative, intuitive, total, symbolic, and potential information. This means that the left hemisphere of the brain is linked to special functions, like language, terms, analysis and classifications. While the right hemisphere is linked to arts, music, addressing the place and the recognition of faces and shapes, it is responsible for the creative activity in human being. While the right pattern is specialized in the creative thinking, the left pattern is specialized in the logical thinking, and this applied on the activity and the nature of sports activity. All these skills lead to increase the level of emotional intelligence for the students. And this can be explained by nature of sports, physical activity, and applied scientific lectures which increase an interaction among students, making social relations and achieving accordance among students. It also gives a real opportunity to develop students' personality. The physical curriculums and courses are full of effective elements in the emotional intelligence.

In 2006 Bar-on indicated to the person who has social and emotional intelligence is able to understand himself and others, he can also face challenges of life and a daily pressure, and this enhances student's physical education and physical activity.

The result agrees with Al_Qadomi study which indicated to a high level of emotional intelligence among police officers [28]. It also agrees with (Al_Zainat; Al-Meziani) their studies indicated to an average level of emotional intelligence among students [18] [19].

\section{Conclusions}

1. In generally the integrated brain dominance was the common patterns in students.

2. The independent variables (gender, specialization, academic year) didn't affect the brain dominance patterns (left, right, integrated).

3. The level of the emotional intelligence differs according to the brain dominance patterns (left, right, integrated) and in favour of right -brain dominance. 


\section{REFERENCES}

[1] Qadumi A, "Brain Dominance among Soccer Players in Palestine" Journal of Educational and Psychological Science, vol.11, no.4, pp. 257-276, 2010. DOI: http://dx.doi.org/10.1 2785/JEPS/110409

[2] Springer S., Deutsc, "GLeft Brain - Right Brain", $5^{\text {th }}$ ed, WH free man and company, (2003).

[3] Omer H., Kadori, I, "The Effective of Feedback Auditory and Optical According to Brain Controlling Right and Left for Dynamic Streaming on Learn Passing through a Hurdle for $110 \mathrm{~m}$ Running Hurdles ages 15 - 16 Years", Al-Qadisiyah Journal of Physical Education Sciences, Iraq, vol. 15, no. 2, pp. 25-33, 2015. DOI: https://iasj.net/iasj/article/110296

[4] Abraham A.,Pieritz K.,Thybusch K., Rutter B., Kroger S., Sehweckendiek J., Stark R., Windmann, S., Herman C, "Creativity and the Brain: Uncovering the Neural Signature of Conceptual Expansion", Neuropsychological, vol. 50, no. 8, pp. 1906- 1917, 2012.DOI:https://doi.org/10.1016/j.neuro psychologia.2012.04.015

[5] Asch M, "Textbook of Cognitive Psychology", New Delhi: Sarup \& Sons, 2002.

[6] Solso R, "Cognitive Psychology", $6^{\text {th }}$ ed. Singapore: Pearson Education, 2004.

[7] Razumnikova O, "Functional Organization of Different Brain Areas during Convergent and Divergent Thinking: An EEG Investigation", Cognitive Brain Research, vol. 10, pp.11- 18, 2000. DOI: 10.1016/s0926-6410(00)00017-3

[8] Torrance E, "Implications for Whole-Brained Theories of Learning and Thinking for Computer- Based Instruction", Journal of Computer- Based Instruction, vol. 7, no. 4, pp. 99-105, 1981. DOI: https://eric.ed.gov/?id=EJ248984

[9] Weinstein S., Graves R, "Are Creativity and Schizotypy Products of Right Hemisphere Bias" Brain and Cognition, vol. 49, pp. 138-151, 2002. DOI: 10.1006/brcg.2001.1493

[10] Bowden E., Jung-Beeman M, "Getting the Right Idea: Semantic Activation in the Right Hemisphere May Help Solve Insight Problems", Psychological Science, vol. 9, pp. 435- 443, 1998. DOI:https://doi.org/10.1111/1467-9280.000 82

[11] Jensen E, "Brain-Based learning", Store San Diego, USA, 2001.

[12] McCarthy B, "The 4 Mat System Research: Review of the Differences and Hemispheric Specialization and their Influence on Learning", Wauconda.IL, 1996.

[13] Al-Harthy, I, "Thinking, Learning and Memory in the Light of Brain Research", Riyadh, 2001.

[14] Bert S., John Y, "Attentional Processes of High-Skilled Soccer Players with Congenital Hemiparesis: Differences Related to Side of the Hemispheric Lesion", Motor Control, vol.12, no.1, pp. 55 - 66, 2008. DOI: https://doi.org/10.1123/mcj.12.1.55

[15] Sham'on, M, "Mental Training in the Sports Field", Cairo, Dar Al Fiker Al Arabi, 2001.
[16] Mezyan, M., Zakai, N, "The Contribution of the Learning Environment on Reinforcing the Hemispheric Dominance", Journal of Educational and Psychological Science, vol. 4, no. 4, pp. 8-36, 2003.

[17] Al-Sumairat, G, "the Relationship between Emotional Intelligence and Students Achievement at Mutah University", Master thesis, Mut'ah University, 2005.

[18] Robins P., Scott J, "Emotional Intelligence", Translated by Al-Aser, Safaa \& Kafafi, Alaa. Qebaa House for Publishing and Distribution, Cairo, 2000.

[19] Al -Zeenat O, "The Relationship between Procrastination and Emotional Intelligence among Yarmouk University Students", Master thesis, Yarmouk University, 2015.

[20] Al-Meziani A, "Emotional intelligence and its Relationship of the Dealing Methods with Psychological Stress in Delinquent Juveniles - Inmates of Re-education Institutions", Center for Generation of Scientific Research, vol. 6, pp. 65-84, 2015.

[21] Othman H, "Effective Sentimental- Passive -Emotional Intelligence - Concepts and Applications", Debono for Printing and Publishing. Amman, Jordan, 2009.

[22] Rabih A, "the Social Intelligence of Employees of some Universities in the Sudanese State of Khartoum" The Arab Journal for the Development of Excellence, Sudan, vol. 2, pp. 7-19, 2011.

[23] Samadoni I, "Emotional Intelligence: its Foundations, Applications and Development", Dar Al Fikr for Printing, Publishing and Distribution, Amman, 2007.

[24] Jabbar A, "Sports Intelligence", Amman, Zahran Publishing House, 2006.

[25] Goldman D, "Emotional intelligence, why it can matter more than IQ", Bantam Books: New York, 1995.

[26] Hamoda A, "The Relationship between the Prevailed Brain Dominance Styles and Meta Cognitive Thinking Level among Al-Azhar University Students", Master Thesis, Gaza, 2015.

[27] Diane c, "Hemispheric dominance", 2005, translated by Qadumi, 2010, Available at: http://www.qcc.cuny.edu/socia lsciences/JCulkin/ss510/hemispheric_dominanceasp.

[28] Othman F., Rizk M, "Emotional Intelligence: Understanding and Measuring", Journal of Psychology, Egypt, vol. 15, no. 58 , pp. 32-51,2001.

[29] Qadumi A, "The Relationship between Emotional Intelligence and Brain Dominance amongst Police Officers in Palestinian", Journal of Science and Humanities, vol. 32, pp. 1-32, 2017. https://staff.najah.edu/en/publications/9793/

[30] Al-Rantesi H, "Brain Dominance, Learning Style and their Relationship to Metacognitive Thinking among Mutah University Students". Master Thesis, Mutah University, 2013.

[31] Al-Qur'an S., Al-Hamouri, K, "Common Brain Dominance Patterns among Ordinary and Outstanding Students in the Preparatory Year at the Qaseem University", Mu'tah Lil Buhuth Wid-Dirasat Journal, vol.28, no. 2, pp.11-32, 2013.

[32] Ozrail R, "The Relationship between Brain Dominance and 
level of Possessiveness among Volleyball Players in Palestine", Master thesis, An Najah National University, 2012.

[33] Nofal M, "the Relationship between Brain Dominance and the Academic Specialization of Students in Schools and Universities in Jordan", An Najah University Journal, vol. 21, no. 1, pp. 1-26, 2007. https://journals.najah.edu/article/7 $25 /$

[34] Al-Hamouri F, "Measuring the Role of Right and Left Hemispheres in Processing Arabic by the Methods of Visual field and Dual-Task Performance",Jordan Journal of Educational Sciences, Yarmouk University, vol. 2, no.1, pp. 11-21,2006.http://journals.yu.edu.jo/jjes/Issues/2006/Vol2N o1.pdf

[35] Talafhah F., Al-Zghoul E, "the Preferred Learning Styles of Mutah University Students and their Relationship to Gender and Specialization", Damascus University Journal for Educational and Psychological Sciences, vol. 25, no.1, pp. 269-297, 2009.
[36] Abdelhaq Z., Al-Ajeli S, "Brain Dominance and its Relationship to Creative Thinking among University Students in Jordon in the Light of Some Demographic Variables", Jordanian journal of educational science, vol. 11, no.2, pp. 239-3254, 2013.http://journals.yu.edu.jo/jjes/Issue s/2015/Vol11No2/8.pdf

[37] Sulaymani M, "Patterns of Information Processing for the two Hemispheres of the Brain and Learning Methods among a Sample of Third-Secondary Students from Makkah city", Master Thesis, Umm Al-Qura University, Kingdom of Saudi Arabia, 2013.

[38] Al-Shehri H, "Patterns of Learning and Thinking among Taiba Students University of Umm Al-Qura University", Journal for Educational and Psychological Sciences, vol. 1, no.2, pp. 353-400, 2009.

[39] Ghossoub, Z., Nadler R., El-Aswad N, "Emotional Intelligence, Resilience, Self-care, and Self-leadership in Healthcare Workers Burnout: A Qualitative Study in Coaching", Universal Journal of Public Health, USA, 8(5): 155-162, 2020. DOI: 10.13189/ujph.2020.080501 